\title{
ESTADIOS FENOLÓGICOS DE DESARROLLO EN "ÑANGAPIRÍ" (Eugenia uniflora L.) DE ACUERDO A LA ESCALA BBCH
}

\author{
Castro, D. C..$^{1 ;}$ Abelvey, E. C. ${ }^{1} ;$ Richard, G. A. ${ }^{2} ;$ Gabriel, P. ${ }^{1} ;$ \\ Alvarez, N. ${ }^{1} ;$ Buyatti, M. ${ }^{1}$ \& Gariglio, N. ${ }^{1}$
}

\begin{abstract}
RESUMEN
Este trabajo estudió los estadios fenológicos de desarrollo en Eugenia uniflora L., un Berry nativo de Sudamérica que tiene importancia económica en mercados locales vinculados a los productores familiares en Brasil, Uruguay y Argentina. Los datos se recolectaron de una plantación de esta especie ubicada en el campo experimental de la Facultad de Ciencias Agrarias de la Universidad Nacional del Litoral (Esperanza, Santa Fe, Argentina. S 31²3’59”; W 6053’58”). Se adaptó la escala $\mathrm{BBCH}$ a $E$. uniflora, registrando los estadios fenológicos con números de dos dígitos; el primero correspondiente al estadio principal de desarrollo y el segundo al estadio secundario de desarrollo, dentro del principal. Se observaron ocho estadios principales de desarrollo: el primero correspondió al desarrollo de las yemas vegetativas y florales (estadio principal 0), los siguientes tres correspondieron al desarrollo vegetativo abarcando la emergencia de las hojas (estadio principal 1), la elongación de los brotes (estadio principal 3) y el cese invernal del crecimiento (estadio principal 9). Los últimos cuatro estadios correspondieron al desarrollo reproductivo e incluyeron la emergencia de los órganos reproductivos (estadio 5), la floración (estadio 6), el crecimiento del fruto (estadio 7) y su madurez (estadio 8).
\end{abstract}

Key words: Mirtáceas, Cereza de Cayena, estados de desarrollo, frutales nativos, Arrayán.

1.- Cátedra de Cultivos Intensivos. Facultad de Ciencias Agrarias. Universidad Nacional del Litoral. Kreder 2805. (3080) Esperanza, provincia de Santa Fe. Argentina.

2.- CONICET. Cátedra de Botánica Sistemática Agronómica. Facultad de Ciencias Agrarias. Universidad Nacional del Litoral. Kreder 2805. (3080) Esperanza, provincia de Santa Fe. Argentina.

Manuscrito recibido el 4 de julio de 2018 y aceptado para su publicación el 14 de septiembre de 2018.

Castro, D.C.; Abelvey, E.C.; Richard, G.A.; Gąbŗiel, P.; Álvarez, N.; Buyatti, M. \& Gariglio, N. Estadios fenológicos de desarrollo en "Ñangapiri" (Eugenia uniflora L.) de acuerdo a la escala BBCH.

FAVE - Ciencias Agrarias 17 (2): 7-21. CC BY-NC-SA 4.0 (c) (1) (2) 


\section{ABSTRACT \\ Phenological growth stages of Pitanga (Eugenia uniflora L.) according to the $\mathrm{BBCH}$ scale.}

This research studied the phenological growth and development stages of Eugenia uniflora L., a native South American species whose berries have economic relevance in markets linked to family farmers in Brazil, Uruguay and Argentina. Data were collected from a plantation of this species growing in the experimental field of the Facultad de Ciencias Agrarias of the Universidad Nacional del Litoral (Esperanza, Santa Fe, Argentina. S 3123‘59”; W 6053’58”). We adapted the BBCH-scale for E. uniflora, and the phenological stages were coded using two digits; the first corresponding to the principal growth stages, and the second corresponding to the secondary growth stage, within the principal. Eight principal growth and development stages were recognized starting with vegetative and flower bud development (stage 0 ). The following three of them were assigned to the vegetative growth, which described leaf development on shoots (stage 1), shoot elongation (stage 3) and winter growth cessation (stage 9). The last four principal growth stages describe flower emergence (stage 5), flowering (stage 6), fruit development (stage 7) and maturity (stage 8).

Key words: Myrtaceae, Pitangueira, Developmental stages, Brazilian cherry, Surinam Cherry

\section{INTRODUCCIÓN}

Actualmente, a nivel regional existe un gran interés de productores familiares por los frutos de especies nativas en general, y los berries en particular, dado su enorme valor nutricional (13). Muchos berries nativos presentan altos contenidos de polifenoles y elevada capacidad antioxidante, cuestiones que contribuyen a prevenir enfermedades crónicas de alta incidencia, como el cáncer y enfermedades cardiovasculares (32). Es por ello que la industria alimentaria de países de la región los utiliza en sus formulaciones alimenticias como nutracéuticos para la prevención de estas enfermedades (9). Argentina posee en sus bosques nativos una elevada diversidad de especies cuyos frutos pueden clasificarse como "berries" (denominación comercial que refiere a "bayas", "frutos del bosque", o "frutas finas"), entre los cuales se encuentra Eugenia uniflora L. ("Ñangapirí", "Pitanga” o “Arrayán”). El “Ñangapirí” es una especie nativa arbórea de hoja perenne y pequeño porte de la familia Myrtaceae, con amplia distribución en Sudamérica (35). En Argentina es parte de los bosques mixtos del "Chaco húmedo" como especie co-dominante del estrato arbustivo (22), pero su distribución geográfica excede la región Chaqueña, encontrándose presente en las provincias de Salta, Tucumán, Jujuy (selva de las "Yungas"), Misiones ("Selva Paranaense") y Entre Ríos (como parte de la selva asociada a los ríos Paraná y Uruguay) (12). La familia Myrtaceae posee muchos géneros de importancia en la industria frutícola como Psidium, Acca, Syzygium, Feijoa, Campomanesia, Myricaria y Eugenia 
(24). Las especies con mayor relevancia económica actual son Psidium guajava (“Guayabo”) y Acca sellowiana ("Guayabo del País”, “Zeijoa”, “Goiaba serrana”) (1, 3, 19, 24). No obstante, Eugenia uniflora es un frutal emergente, principalmente en Brasil $(16,35)$ y Uruguay (Vignale, comunicación personal), donde se encuentran selecciones que se cultivan comercialmente $(6,7,23)$. En nuestro país esta especie tiene importancia local en las provincias de Tucumán, Salta, Misiones y Corrientes, como subsidio alimenticio de pobladores locales o para la producción de dulces $(14,20,21,31)$. No obstante, existen esfuerzos estatales para formalizar su aprovechamiento como Producto Forestal No Maderero, principalmente en la región NOA y NEA (26, 34).

Los frutos de Eugenia uniflora son comestibles $(27,35)$ y existen desarrollos tecnológicos patentados vinculados a sus usos alimenticios, farmacéuticos y cosméticos $(10,28,36)$. Desde el punto de vista nutricional y funcional, los frutos del "Ñangapirí” son ricos en compuestos volátiles con propiedades terapéuticas (25), poseen un alto contenido de compuestos fenólicos con elevada capacidad antioxidante (8), y un alto contenido de carotenoides, que superan lo encontrado en "Uva" (Vitis vinifera), “Mora” (Morus nigra), “Melón” (Cucumis melo), "Guayaba" (Psidium guayaba) y "Papaya” (Carica papaya) (5).

El aprovechamiento de este "Berry" podría realizarse a partir del manejo de los bosques nativos, ya que es una especie que domina el sotobosque de los bosques del Chaco oriental, de la selva Paranaense y de la selva de las Yungas, o de su producción en cultivo como frutal. Independientemente del modelo de aprovechamiento de esta especie, un aspecto importante para el manejo productivo de un frutal es la estan- darización de los estadios fenológicos más importantes. Esto permite prescribir determinadas prácticas de manejo como riego, fertilización, aplicación de fitosanitarios y reguladores del crecimiento, introducción de colmenas para polinización, raleo de flores y/o frutos y la cosecha de los mismos de manera más eficiente y en los momentos más apropiados para el cultivo. En Brasil se han realizado estudios de calidad de frutos $(8,11)$ y alteraciones fisiológicas durante el almacenamiento $(29,30)$ en frutos de E. uniflora en estadios fenológicos determinados, pero dichos estadios no son uniformes entre los trabajos en la bibliografía y tampoco con las observaciones realizadas en los genotipos de poblaciones santafecinas. Esta discrepancia podría deberse a distintos criterios de observación o a diferencias en los genotipos evaluados. Por otro lado, no existen trabajos que estandaricen la fenología de E. uniflora en otros momentos de desarrollo, además del estadio de madurez de los frutos.

El objetivo de este trabajo fue adaptar la escala fenológica BBCH a E. uniflora con el propósito de facilitar su manejo productivo.

\section{MATERIALES Y MÉTODOS}

\section{Material vegetal}

Los datos fueron tomados a partir de genotipos de E. uniflora de 3 años de edad producidos a partir de semillas de plantas provenientes de una población natural ubicada en el Paraje "Las Claritas" de la provincia de Santa Fe (S 28³3'42,5”; W 59³3'38,2”). Las plantas se encontraban cultivadas en el Campo Experimental de Cultivos Intensivos y Forestales de la Facultad de Ciencias Agrarias de la Univer-

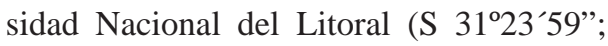




\section{C. Castro et al.}

W 6053'58”), en un marco de plantación de $1,5 \mathrm{~m}$ x $3 \mathrm{~m}$ y fueron regadas con riego por goteo complementario, en función de las necesidades del cultivo. Al momento de la evaluación, las plantas se encontraban en plena producción de frutos. El clima de la región corresponde al tipo Cfa (templado húmedo sin estación seca con veranos muy calurosos), según la clasificación de Köppen (15) con una temperatura media de $18,9^{\circ} \mathrm{C}$, una mínima media de $12,6{ }^{\circ} \mathrm{C}$ y una máxima media de $25,3^{\circ} \mathrm{C}$. El mes más cálido es Enero, con una temperatura media de 25,8 ${ }^{\circ} \mathrm{C}$ y el mes más frío es Julio con una media de $12,4{ }^{\circ} \mathrm{C}$. La precipitación total de la zona ronda los $950 \mathrm{~mm}$. Las observaciones fueron realizadas durante 2016 y 2017.

\section{Características de la escala BBCH}

La escala fenológica $\mathrm{BBCH}$ permite ser aplicada a especies para las cuales no existe una escala individual. Según esta escala, existe una estructura común para todas las especies en función de la cual el ciclo completo de desarrollo de las plantas se subdivide en diez fases principales de desarrollo claramente distinguibles, que a su vez pueden sub-dividirse en estadios secundarios o terciarios(17), mucho más precisos en términos temporales y que pueden ser utilizados para prescripciones de manejo (Figura 1). Los estadios principales y secundarios de crecimiento, son descritos usando números del 0 al 9 en orden ascendente, conforme avanza el desarrollo. Aun-

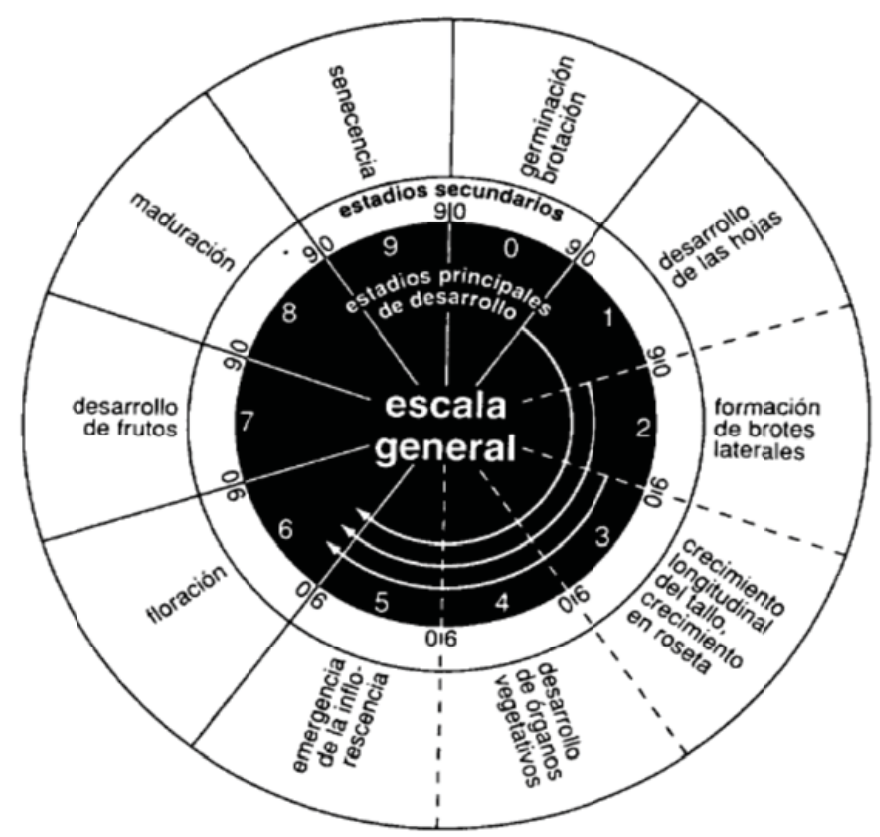

Figura 1. Ciclo de desarrollo de las plantas según la escala fenológica BBCH. Se observan 10 estadios de desarrollo principales, los cuales a su vez se dividen en 10 estadios secundarios, dentro de cada estadio principal. La combinación de los estadios principales y secundarios resulta en una codificación de dos cifras; la primera indicando el estadio principal y la segunda indicando el estadio secundario, dentro de cada estadio principal.

Tomado de (17). 
que la escala tiene un orden numérico, los estadios no siempre ocurren en la secuencia enumerada; puede suceder que algunos estadios no se observen o que dos o más estadios se presenten de forma simultánea. La escala BBCH se construye a partir de la observación del proceso de desarrollo en plantas individuales, pero su utilización puede realizarse en plantas individuales 0 en poblaciones de plantas. Para adaptar la escala BBCH a E. uniflora, se seleccionaron 20 plantas y se realizó una observación fenológica 2 a 3 veces por semana desde el período de reposo (antes de la brotación) hasta la senescencia de los frutos y la culminación del crecimiento de los brotes vegetativos, con el fin de establecer los estadios principales y describir los estadios secundarios. Estas observaciones se realizaron sobre ramos representativos de cada planta y se realizó un registro fotográfico de la información relevada.

\section{Determinación de la receptividad} estigmática

Con objeto de darle precisión a la escala $\mathrm{BBCH}$ sobre el momento de receptividad estigmática y liberación de polen, en la etapa de floración se recolectaron 20 flores por estadio en distintos sub-estadios del estado principal 6 (floración) en tubos falcon de 50 mL para prevenir la desecación. Posteriormente se llevaron al laboratorio para evaluar la receptividad del estigma utilizando peróxido de hidrogeno y guaiacol (33). En una caja de petri bajo la lupa se colocaron las flores inmersas en una solución de peróxido de hidrogeno y guaiacol; este método se basa en la reacción de la enzima peroxidasa al colocar una gota de peróxido de hidrógeno al $40 \%$ sobre los estigmas de las flores, lo que origina la producción de burbujas y tinción a color rojizo del estigma, si éste se encuentra receptivo. Si se observa burbujeo conspicuo y tinción rojiza al mismo tiempo en el estigma, se asume que está receptivo (Figura 2).

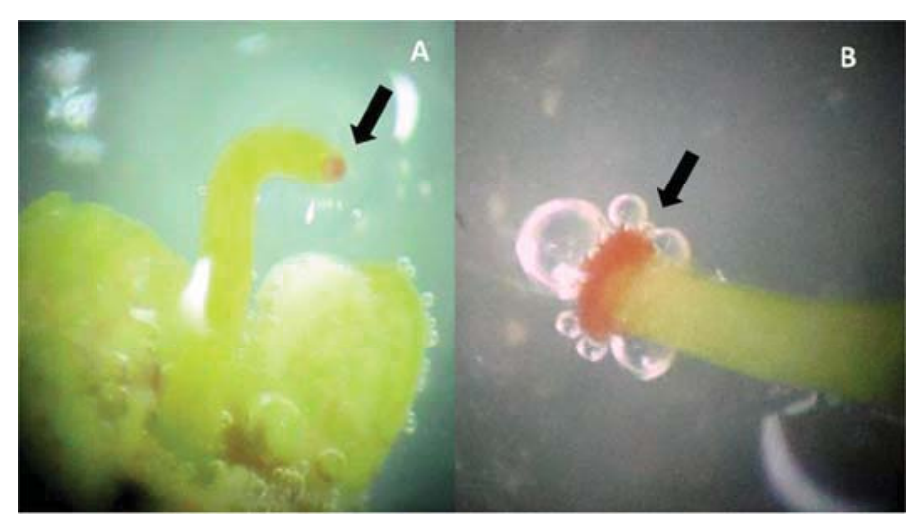

Figura 2. Receptividad estigmática en E. uniflora por medio del test de guaiacol- $\mathrm{H}_{2} \mathrm{O}_{2}$ (A) Estigma no receptivo dado que se produce la coloración rojiza pero no se observa burbujeo. (B) Estima receptivo; se observa tinción rojiza y burbujeo. 


\section{C. Castro et al.}

\section{RESULTADOS Y DISCUSIÓN}

La estructura de la escala BBCH plantea 10 estadios principales de desarrollo, sin embargo no todos fueron observados en $E$. uniflora, coincidente con lo descripto para otras plantas leñosas perennes (2, 18). En efecto, el estadio 2 ("formación de brotes laterales/macollaje”) no corresponde a plantas leñosas y no se observó la producción de estructuras de propagación vegetativa (estadio principal 4; "desarrollo de partes vegetativas cosechables o de órganos vegetativos de propagación”), a diferencia de Berberis buxifolia "Calafate", otro "Berry" nativo de Argentina(4).

De los 8 estadios observados, el primero corresponde al desarrollo de las yemas (estadio 0), los siguientes dos corresponden al crecimiento vegetativo, que describe el desarrollo de las hojas en los brotes (estadio 1) y la elongación de dichos brotes (estadio 3), los siguientes 4 describen el desarrollo reproductivo abarcando la aparición del órgano floral (estadio 5), la antesis (estadio 6), la fructificación (estadio 7) y la maduración de los frutos (estadio 8). El estadio restante describe el proceso de reposo vegetativo de las yemas, o parada invernal del crecimiento, que en el caso de E. uniflora no estaría relacionado a un proceso de endo-latencia en yemas, sino posiblemente a eco-latencia (estadio 9).

\section{Estadio principal 0: desarrollo de las} yemas

La escala comienza con el valor 00 que representa el estado latente de las yemas (Tabla 1). E. uniflora es un árbol de pequeño porte de hoja perenne que detiene su crecimiento vegetativo en invierno. En este período las yemas están cubiertas por escamas de color grisáceo (estadio 00. Figura 3). Posteriormente las yemas comienzan a hincharse (estadio 01, Figura 3), proceso que finaliza con la apertura de las escamas y posteriormente el comienzo de la brotación, mostrando un crecimiento vegetativo inicial de color rojizo (estadio 07, Figura 3). Este estadio principal culmina con la aparición de los primordios foliares (estadio 09, Figura 3). Durante el año que duró el estudio, este estadio principal fue observado desde mediados hasta fines de agosto.

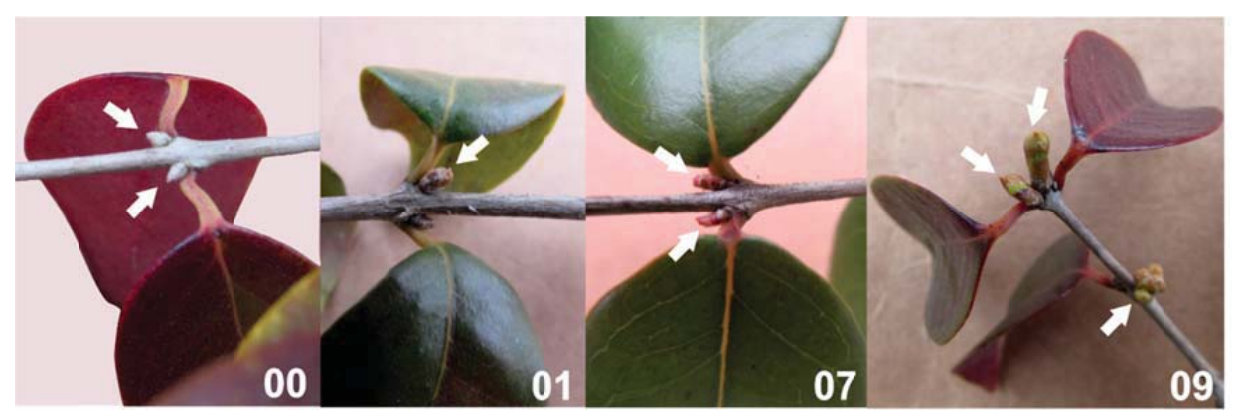

Figura 3. Estadios fenológicos de desarrollo en Eugenia uniflora (L.) registrados en Santa Fe, Argentina. Imágenes del estadio principal 0, correspondiente a la escala BBCH. Las flechas indican las yemas en crecimiento 
Estadios fenológicos de desarrollo en "Ñangapirí"

Tabla 1. Estadios fenológicos observados en E. uniflora y codificados según la escala BBCH. La primera cifra del código corresponde al estadio principal de desarrollo, mientras que la segunda corresponde al estadio secundario de desarrollo

\begin{tabular}{|c|c|c|}
\hline Estadio principal & Código & Descripción \\
\hline \multirow[t]{5}{*}{ o Desarrollo de las yemas } & 00 & Reposo. Yemas apicales y laterales totalmente cerradas. \\
\hline & 01 & Comienzo del hinchado de yemas. \\
\hline & 03 & Fin del hinchado de yemas. \\
\hline & 07 & Comienza la apertura de yemas (brotación) \\
\hline & 09 & Fin de la brotación \\
\hline \multirow[t]{4}{*}{1 Desarrollo de las hojas } & 10 & Primeras hojas separándose \\
\hline & 15 & Más hojas en expansión \\
\hline & 17 & Las primeras hojas alcanzan el tamaño máximo \\
\hline & 19 & todas las hojas completamente abiertas y expandidas \\
\hline \multirow[t]{4}{*}{3 Desarrollo de los brotes } & 31 & Comienza el crecimiento de los brotes \\
\hline & 32 & Los brotes tienen aproximadamente $15-20 \%$ de su longitud final \\
\hline & 35 & Los brotes tienen aproximadamente $50 \%$ de su longitud final \\
\hline & 39 & Los brotes tienen aproximadamente $90 \%$ de su longitud final \\
\hline \multirow[t]{4}{*}{5 Aparición del órgano floral } & 51 & Las escamas de las yemas están abiertas \\
\hline & 52 & Botones florales en crecimiento. \\
\hline & 53 & Los botones florales siguen elongándose. Botón verde. \\
\hline & 59 & $\begin{array}{l}\text { Los botones florales alcanzan su tamaño máximo. Estigma } \\
\text { receptivo. Balón rosado. }\end{array}$ \\
\hline \multirow[t]{6}{*}{6 Floración } & 60 & Primeras flores abiertas \\
\hline & 61 & Pétalos y sépalos abiertos a $45^{\circ}$ \\
\hline & 62 & $\begin{array}{l}\text { Pétalos y sépalos en posición horizontal. Comienza liberación } \\
\text { de polen. }\end{array}$ \\
\hline & 65 & Plena floración (50\% de las flores abiertas). \\
\hline & 67 & Flores marchitándose \\
\hline & 69 & Fin de floración \\
\hline \multirow[t]{3}{*}{7 Desarrollo de los frutos } & 70 & Cuajado de frutos \\
\hline & 75 & $50 \%$ del tamaño final de los frutos \\
\hline & 79 & $100 \%$ del tamaño final \\
\hline 8 Madurez de los frutos & 81 & Comienza el viraje de color a amarillo \\
\hline \multirow{5}{*}{$\begin{array}{l}9 \text { Comienzo del reposo } \\
\text { vegetativo }\end{array}$} & 82 & Fruto de color naranja \\
\hline & 83 & Fruto de color rojo \\
\hline & 89 & Fruto de color morado \\
\hline & 91 & $\begin{array}{l}\text { Culmina el crecimiento de brotes. Empiezan a formarse las } \\
\text { yemas apicales. }\end{array}$ \\
\hline & 99 & $\begin{array}{l}\text { Se detiene el crecimiento durante el invierno. Se observan la } \\
\text { mayoría de las yemas apicales y laterales formadas. }\end{array}$ \\
\hline
\end{tabular}




\section{C. Castro et al.}

\section{Estadio principal 1: desarrollo de las hojas}

Luego de que las yemas abren, comienza la separación de las primeras hojas (estadio 10, Figura 4). Conforme tiene lugar el desarrollo del brote, se observa la expansión de las primeras hojas, de color rojizo (estadio 15, Figura 4). Este estadio termina con la expansión completa de las primeras hojas (estadio 19). Durante la realización de este estudio, este estadio principal fue observado durante la primera semana de septiembre.

\section{Estadio principal 3: desarrollo \\ de los brotes}

Este estadio comienza cuando se hace visible el primer nudo de crecimiento de los brotes (estadio 31, Figura 5). La elongación de los brotes continúa en simultáneo con el inicio de la floración, y culmina antes del período de reposo invernal (estadio 39). Durante la realización de este trabajo, este estadio principal fue observado a partir de la segunda semana de septiembre (desde el 6/9 en adelante).

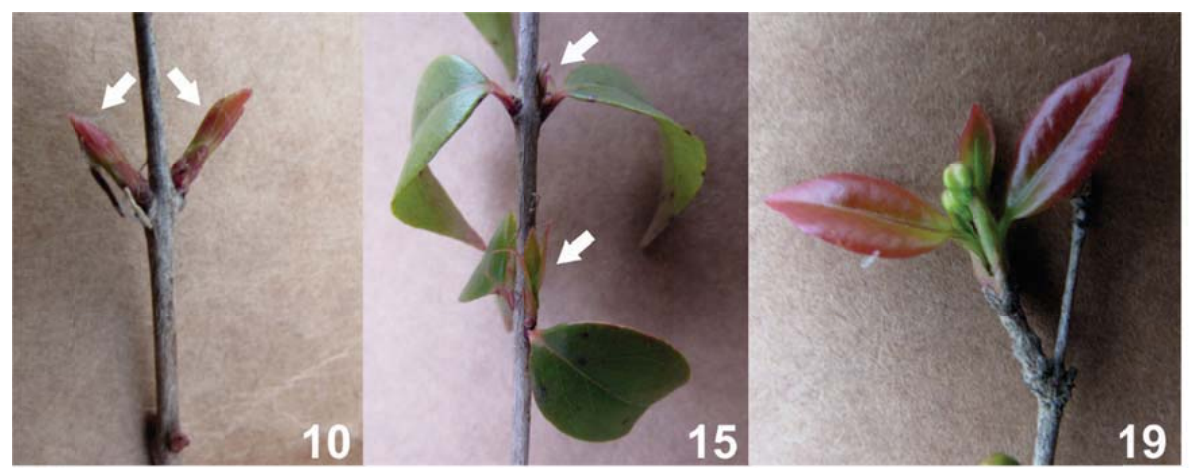

Figura 4. Estadios fenológicos de desarrollo en Eugenia uniflora (L.) registrados en Santa Fe, Argentina. Imágenes del estadio principal 1, correspondiente a la escala BBCH. Las flechas indican las hojas en crecimiento.

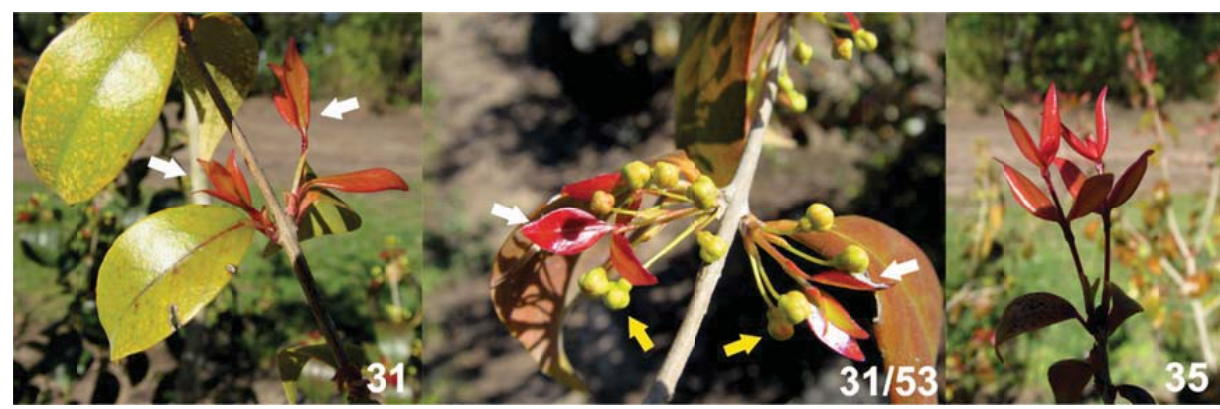

Figura 5. Estadios fenológicos de desarrollo en Eugenia uniflora (L.) registrados en Santa Fe, Argentina. Imágenes del estadio principal 3, correspondiente a la escala $\mathrm{BBCH}$. Las flechas blancas indican el desarrollo de los brotes. Las flechas amarillas indican los botones florales del estadio 53; el estadio 3 y el 5 ocurren simultáneamente. 


\section{Estadio principal 1: desarrollo de las hojas}

Luego de que las yemas abren, comienza la separación de las primeras hojas (estadio 10, Figura 4). Conforme tiene lugar el desarrollo del brote, se observa la expansión de las primeras hojas, de color rojizo (estadio 15, Figura 4). Este estadio termina con la expansión completa de las primeras hojas (estadio 19). Durante la realización de este estudio, este estadio principal fue observado durante la primera semana de septiembre.

\section{Estadio principal 3: desarrollo de los brotes}

Este estadio comienza cuando se hace visible el primer nudo de crecimiento de los brotes (estadio 31, Figura 5). La elongación de los brotes continúa en simultáneo con el inicio de la floración, y culmina antes del período de reposo invernal (estadio 39). Durante la realización de este trabajo, este estadio principal fue observado a partir de la segunda semana de septiembre (desde el 6/9 en adelante).

\section{Estadio principal 5: Aparición del órgano floral}

Una vez que las escamas de las yemas se abren y ocurre la brotación de las yemas florales, se observan botones florales de color verde que están muy próximos entre sí, con apariencia de estar soldados (Estadio 51, Figura 6). Posteriormente, se produce la elongación de los pedicelos de los botones florales pudiendo distinguirse individualmente cada uno; se observan claramente los sépalos verdes cerrados (estadio 52, Figura 6). En este estadio se advierte el inicio del crecimiento de los brotes vegetativos. El desarrollo de los botones florales continúa, observándose una apertura inicial de los sépalos, poniendo al descubierto el ápice de los pétalos cerrados, de color blanco; en este estadio los sépalos y los pétalos tienen aproximadamente el mismo tamaño (estadio 53, Figura 6) y continúa el crecimiento de los brotes vegetativos (estadio 31/53 de la Figura 5). La aparición del órgano floral culmina cuando los botones florales alcan-

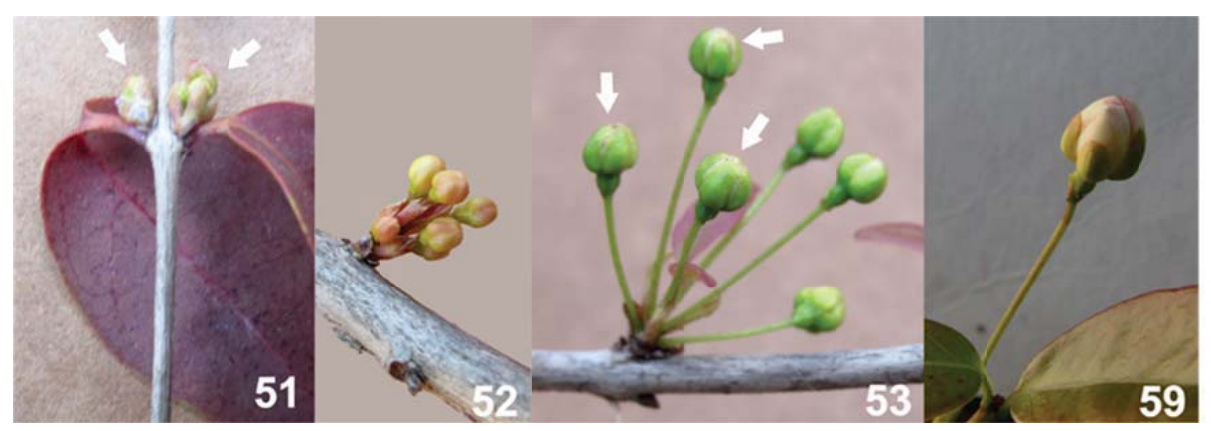

Figura 6. Estadios fenológicos de desarrollo en Eugenia uniflora (L.) registrados en Santa Fe, Argentina. Imágenes del estadio principal 5, correspondiente a la escala BBCH. 51) Las flechas blancas indican los botones florales en desarrollo. 53) Las flechas indican el inicio de la apertura de los sépalos, exponiendo en la parte superior a los pétalos. 


\section{C. Castro et al.}

zan su tamaño máximo (estadio 59, Figura 6); los sépalos, que tienen aproximadamente la mitad de tamaño que los pétalos, están completamente abiertos y los pétalos de color rosado-blanco en su cara expuesta se encuentran formando una "bola hueca", pero sin que se hagan visibles los órganos reproductivos. De acuerdo al test de guaiacol- $\mathrm{H}_{2} \mathrm{O}_{2}(33)$ los estigmas ya se encuentran receptivos en el estadio 59 (Figura 2). Sin embargo, resta confirmar si dicha receptividad puede ser observada en el estadio 53, dado que las observaciones realizadas no son concluyentes a este respecto. El comienzo de este estadio principal fue observado en simultáneo con el estadio 3, hacia el final de la primer semana de septiembre.

\section{Estadio principal 6: Floración}

Este estadio comienza con la antesis (estadio 60, Figura 7); se produce la separación de los pétalos en su extremo superior, dejando expuesto el estigma (ya receptivo) y las anteras, todavía cerradas. Posteriormente, los pétalos totalmente de color blanco se abren formando un ángulo de $45^{\circ}$ con la horizontal (estadio 61, Figura 7), al igual que los sépalos. En este estadio, las anteras están a la misma altura que los estigmas, o ligeramente por debajo ya que sus filamentos no se encuentran totalmente elongados. En el estadio 61 pudo constatarse en algunas flores indicios de liberación de polen, no obstante es necesario ampliar el número de flores observadas para confirmar este hecho. La liberación de polen alcanza mayor magnitud posteriormente, cuando se

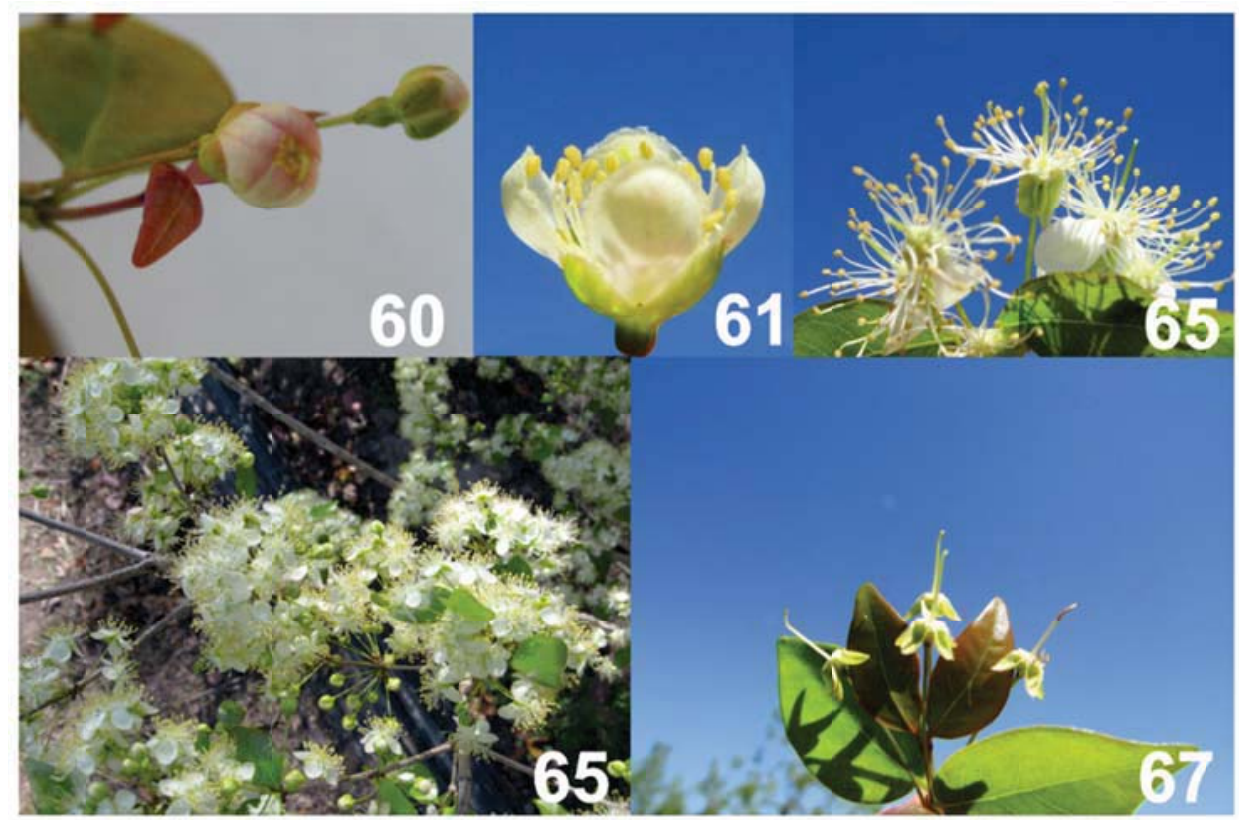

Figura 7. Estadios fenológicos de desarrollo en Eugenia uniflora (L.) registrados en Santa Fe, Argentina. Imágenes del estadio principal 6, correspondiente a la escala BBCH. 
abren más flores y los pétalos y sépalos se hayan en posición horizontal (estadio 62). La plena floración ocurre cuando la mayoría de las flores se encuentra abierta, como mínimo un 50\% (estadio 65, Figura 7). En este estadio la mayoría de las flores liberaron su polen y los pétalos se encuentran en una posición ligeramente por debajo de la horizontal, mientras que los sépalos se encuentran formando un ángulo aproximado de $45^{\circ}$ por debajo de la horizontal. Posteriormente comienza la caída de los pétalos; los pétalos forman un ángulo aproximado de $45^{\circ}$ por debajo de la horizontal al igual que los sépalos (estadio 67). El estadio de floración culmina cuando todos los pétalos han caído; solo persisten en la flor los sépalos completamente hacia abajo y generalmente se observan los estigmas necrosados (estadio 69, Figura 7). Este estadio principal, tuvo lugar durante el mes de septiembre, siendo la plena floración a finales de dicho mes.

\section{Estadio principal 7: Desarrollo de los frutos}

Posteriormente a la caída de pétalos se observa un hinchamiento del ovario, lo que corresponde al cuajado inicial de frutos (estadio 70, Figura 8). Luego se da una fase de crecimiento rápido que concluye cuando el fruto alcanza el $100 \%$ de su tamaño, que en el caso de las plantas evaluadas corresponde a un calibre medio de $11,7 \pm 1,4 \mathrm{~mm}$, pero continúa con una coloración verde (estadio 79, Figura 8). Durante el presente estudio, el inicio de este estadio principal se observó a partir de principios de octubre, observándose el estadio 79 hacia finales de octubre.

\section{Estadio principal 8: Madurez de los frutos}

Cuando comienza la madurez de los frutos, se observa un viraje del color de los frutos hacia el amarillo (estadio 81, Figura 8). Posteriormente el color del fruto cambia a naranja (estadio 82, Figura 8). Estos vira-

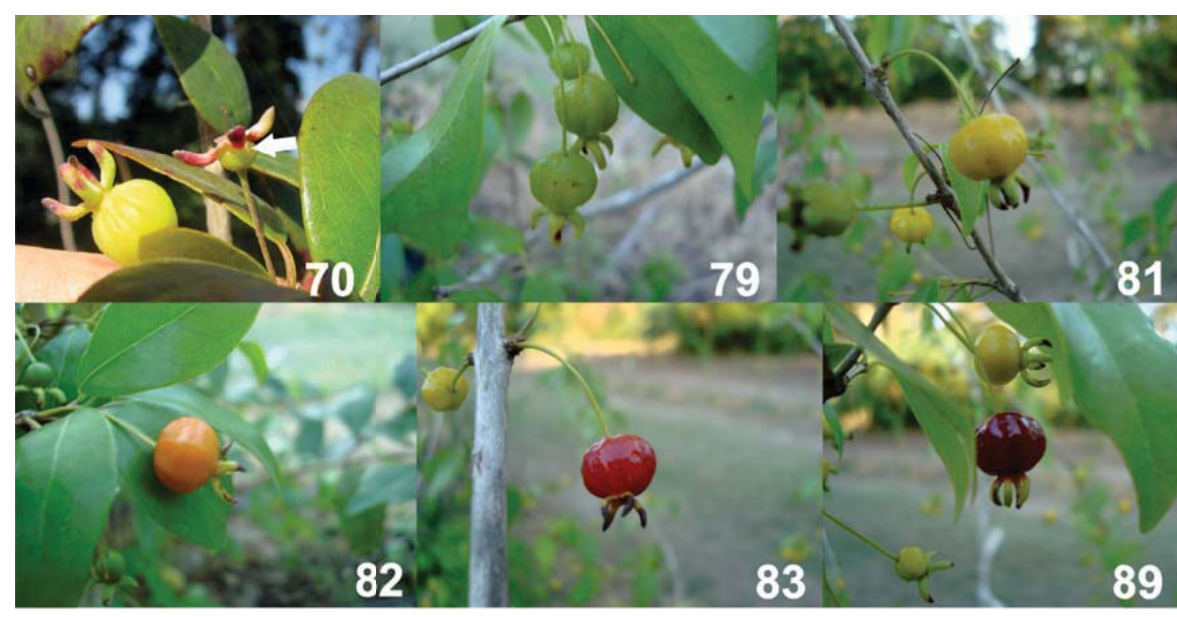

Figura 8. Estadios fenológicos de desarrollo en Eugenia uniflora (L.) registrados en Santa Fe, Argentina. Imágenes de los estadios principales 7 y 8, correspondiente a la escala BBCH. 70) La flecha blanca indica el ovario hinchado. 


\section{C. Castro et al.}

jes de color pueden observarse en la totalidad del fruto en la mitad del mismo. Dada la gran variabilidad encontrada en la maduración de los frutos de E. uniflora, existen plantas cuyo estadio final de maduración de frutos presenta un color rojo (estadio 83, Figura 8) y otras en donde el estadio final de madurez de los frutos es color morado (35). En el caso de las plantas evaluadas, la coloración final fue morada (estadio 89, Figura 8), por lo que a los frutos rojos se los definió bajo el estadio 83. Dada la gran variabilidad dentro de las plantas y entre plantas, es posible observar todos estos estadios de manera simultánea dentro de una planta. Este estadio principal se observó desde la primera semana de noviembre hasta mediados de diciembre, donde los últimos frutos alcanzaron el estadio 89.

Además de la variabilidad en el progreso de los estadios fenológicos de madurez de los frutos, se observó una variabilidad considerable en torno al tamaño de los frutos entre y dentro de plantas (masa media $=$ $1,0 \mathrm{~g} ; \mathrm{CV} \%=40$ ). Esto se debe a que las plantas evaluadas no fueron originadas en un programa de mejora genética, por lo tanto no fueron sometidas a ningún proceso de selección para uniformizar la floración, maduración o tamaño y calidad de los frutos.

Además de lo anterior, existe un comportamiento diferente en cuanto a la maduración de los frutos de los genotipos evaluados en este trabajo, en comparación con genotipos de origen brasileño. En los genotipos evaluados, la madurez de los frutos se observa entre fines de octubre y principios de diciembre. En ocasiones algunos genotipos muestran una fructificación en el mes de junio o julio, siempre y cuando no hayan existido heladas fuertes. En los genotipos brasileños normalmente se observa producción de frutos durante todo el año con dos picos bien marcados; uno entre abril-mayo (21,9 \% de la producción anual) y otro entre agosto y octubre $(60,8 \%$ de producción de la producción anual)(6, 7).

\section{Estadio principal 9: Comienzo del reposo vegetativo}

Una vez finalizada la madurez de los frutos, continúa el crecimiento de los brotes, que culmina, en la mayoría de los casos, cuando se observa la formación de yemas terminales (esto fue observado en junio durante el desarrollo del presente trabajo). En ocasiones se observa que las hojas viejas caen, pero la mayoría de las plantas mantienen su follaje durante el invierno. En esta etapa suele observarse un enrojecimiento de las hojas de aquellos brotes que no culminaron su crecimiento. Se produce una detención del crecimiento de brotes, posiblemente debido a eco-latencia y no a endo-latencia, a partir de junio y hasta mediados de agosto, donde se observa el inicio del estadio 0 .

\section{CONCLUSIÓN}

La escala propuesta es muy útil para estudios futuros de E. uniflora de índole agronómica, eco-fisiológica o de calidad y aprovechamiento de sus frutos. Además esta escala será de utilidad para comparar el comportamiento de esta especie en distintos lugares de cultivo o para comparar el comportamiento de diferentes genotipos en un mismo lugar. Por otro lado, esta escala se constituye en una herramienta para el manejo de esta especie ya que permite estandarizar el momento óptimo para prácticas importantes como riego, aplicación de reguladores del crecimiento, raleo, cosecha de frutos entre otros. 


\section{AGRADECIMIENTOS}

Este trabajo se desarrolló con fondos provenientes de un proyecto de investigación orientada (código: 2010-082-16) financiado por la Agencia Santafecina de Ciencia, Tecnología e Innovación (provincia de Santa Fe, Argentina) y por el proyecto PICT No 2016-0295 financiado por la Agencia Nacional de Promoción Científica y Tecnológica de Argentina. La colecta de semillas y la producción de los plantines implantados en el campo experimental de la Facultad de Ciencias Agrarias se realizaron con fondos del Programa Institucional de la Universidad Nacional del Litoral, titulado "Programa de Documentación, Conservación y Valoración de la flora nativa”.

\section{BIBLIOGRAFÍA}

1.- ACENED PUENTES MONTAÑEZ, G.; CASTRO, A. Y MILENA SERRANO, A. 2015. Market studies for fresh feijoa (Acca sellowiana Berg) produced in Tibasosa town (Boyacá), Colombia. Revista Mexicana de Agronegocios 38: 271-282.

2.- AGUSTÍ, M.; ZARAGOZA, S.; BLEIHOLDER, H.; BUHR, L.; HACK, H.; KLOSE, R. Y STAUSS, R. 1995. Escala BBCH para la descripción de los estadios fenológicos del desarrollo de los agrios (Gén. Citrus). Levante Agrícola: Revista internacional de cítricos 332: 189-199.

3.- AMARANTE, C.V.T. DO Y SANTOS, K.L. DOS. 2011. Feijoa (Acca sellowiana). Revista Brasileira de Fruticultura 33 [en línea] Disponible en: http://www.scielo.br/scielo.php?script=sci_abstract\&pi$\mathrm{d}=$ S0100-29452011000100042\&lng=en\&nrm=iso\&tlng=en. Acceso: 02/07/2018.
4.- ARENA, M.E.; GIORDANI, E. Y RADICE, S. 2013. Phenological growth and development stages of the native Patagonian fruit species Berberis buxifolia Lam. Journal of Food, Agriculture \& Environment 11: 1323-1327.

5.- BAGETTI, M.; FACCO, E.M.P.; PICCOLO, J.; HIRSCH, G.E.; RODRIGUEZ-AMAYA, D.; KOBORI, C.N.; VIZZOTTO, M. Y EMANUELLI, T. 2011. Caracterização físico-quimica e capacidade antioxidante de pitanga (Eugenia uniflora L.). Ciência e Tecnologia de Alimentos 31: 147-154.

6.- BEZERRA, J.E.F.; LEDERMAN, I.E.; PEDROSA, A.C.; DANTAS, A.P. Y DE FREITAS, E.V. 1995. Performance of Surinam cherry, Eugenia Uniflora L. in Pernambuco, Brazil. Acta Horticulturae: 77-82.

7.- BEZERRA, J.E.F.; LEDERMAN, I.E.; JÚNIOR, S.; DA, J.F. Y ALVES, M.A. 2004. Performance of surinam cherry (Eugenia uniflora L.) under irrigation in the Moxotó Valley, Pernambuco State, Brazil. Revista Brasileira de Fruticultura 26: 177-179.

8.- CELLI, G.B.; PEREIRA-NETTO, A.B. Y BETA, T. 2011. Comparative analysis of total phenolic content, antioxidant activity, and flavonoids profile of fruits from two varieties of Brazilian cherry (Eugenia uniflora L.) throughout the fruit developmental stages. Food Research International 44: 2442-2451.

9.- CRUZAT, R.G. Y BARRIOS, E.A. 2009. Libro de valorización: resultados y lecciones en productos agroindustriales ricos en antioxidantes, a base de berries nativos. (González Enei, G., Ed.). Fundación para la Innovación Agraria.

10.- DIOS, M. 2013. Scalp cleansing and treating composition. Patente WO2013142936 A1, recibida el 26 de marzo de 2013, y emitida el 3 de octubre de 2013. http://www.google.com/patents/WO2013142936A1. 
11.- FETTER, M.R.; CORBELINI, D.D.; VIZZOTTO, M. Y GONZALEZ, T.N. 2009. Compostos bioativos e atividade antioxidante de pitanga (Eugenia uniflora L.) em diferentes estádios de maturação. Anais do XVIII Congresso de Iniciação Cientifica, XI Encontro de Pós Graduação, e I Mostra Cientifica da Universidade Federal de Pelotas. Pelotas, Brasil.

12.- FLORA ARGENTINA. PLANTAS VASCULARES DE LA REPÚBLICA ARGENTINA. En: http://www.floraargentina. edu.ar/. Acceso: 02/07/2018.

13.- FREDES, C. 2009. Antioxidantes en berries nativos chilenos. Boletín Latinoamericano y del Caribe de plantas medicinales y aromáticas 8: 469-478.

14.- FREYRE, M.R.; BAIGORRIA, C.M.; ROZYCKI, V.R.; BERNARDI, C.M. Y CHARPENTIER, M. 2000. Vegetales silvestres sub explotados del Chaco argentino y su potencial como recurso alimenticio. Archivos Latinoamericanos de Nutrición 50: 394-399.

15.- GARCÍA, M. S.; LEVA, P.; TÓFFOLI, G.; GARIGLIO, N. Y VALTORTA, V. 2013. Porciones de frio acumuladas en la region centro de la provincia de Santa Fe. Fave. Sección ciencias agrarias 12: 07-11.

16.- GRIFFIS, JR., J.L.; SAMS, C.E.; MANNERS, M.M.; MCDONALD, T.G. Y RADOVICH, T.J. 2013. A progress report on commercialization in the USA of purple-fruited pitanga (Eugenia uniflora L.), an underutilized fruit crop. Acta Horticulturae: 807-814.

17.- HACK, H.; BLEIHOLDER, H.; BUHR, L.; MEIER, U.; SCHNOCK-FRICKE, E.; WEBER, E. Y WITZENBERGER, A. 1992. Einheitliche Codierung der phänologischen Entwicklungsstadien mono- und dikotyler Pflanzen - Erweiterte BBCH-Skala, Allgemein. Nachrichtenblatt des Deutschen Pflanzenschutzdienstes: 265-270.
18.- HERNÁNDEZ DELGADO, P.M.; ARANGUREN, M.; REIG, C.; FERNÁNDEZ GALVÁN, D.; MESEJO, C.; MARTÍNEZ FUENTES, A.; GALÁN SAÚCO, V. Y AGUSTÍ, M. 2011. Phenological growth stages of mango (Mangifera indica L.) according to the BBCH scale. Scientia Horticulturae 130: 536-540.

19.- HUNT, E. 2017, mayo 13. Falling for feijoas: the fruit New Zealand wants the world to love. The Guardian [en línea] Disponible en: http://www.theguardian.com/lifeandstyle/2017/may/13/falling-for-feijoas-the-fruit-new-zealand-wants-the-world-to-love. Acceso: 02/07/2018.

20.- INCUPO. 1998. 2. ${ }^{\text {a }}$ ed. El Monte nos da comida 1: Más de 50 recetas con alimentos silvestres y muchas ideas para aprovecharlos. Talleres gráficos de INCUPO. Reconquista, Santa Fe. Argentina. 72 pp.

21.- INCUPO. 1998. 2. ${ }^{\text {a }}$ ed. El Monte nos da comida 2: Más de 50 recetas con alimentos silvestres y muchas ideas para aprovecharlos. Talleres gráficos de INCUPO. Reconquista, Santa Fe. Argentina. 63 pp.

22.- LEWIS, J..; BARBERIS, I..; PIRE, E.F. Y CARNEVALE, N.J. 2005. Estructura y funcionamiento de los bosques del Chaco Húmedo Santafesino: el Quebrachal de la Cuña Boscosa. En: Goya, J.F.; Frangi, J.L.; Arturi, M.F. (eds.). Ecología y manejo de los bosques de Argentina. Investigación en bosques nativos de Argentina. Editorial de la Universidad Nacional de La Plata (EDULP). La Plata, Buenos Aires, Argentina.

23.- DE LIRA JÚNIOR, J.S.; BEZERRA, J.E.F. Y LEDERMAN, I.E. 2010. Repetibilidade da produção, número e peso de frutos de seleções de pitanga roxa. Acta Agronómica 59: 103-110.

24.- MITRA, S. K. 2010. Important Myrtaceae fruit crops. Acta Horticulturae: 33-38. 
25.- OLIVEIRA, A.L.; LOPES, R.B.; CABRAL, F.A. Y EBERLIN, M.N. 2006. Volatile compounds from pitanga fruit (Eugenia uniflora L.). Food Chemistry 99: 1-5.

26.- PROYECTO PNUD: BOSQUES NATIVOS Y COMUNIDAD. (s. f.). En: http:// www.ar.undp.org/content/argentina/es/ home/operations/projects/environment_and_ energy/manejo-y-conservacion-de-los-bosques-nativos.html. Acceso: 14/03/2017.

27.- RAGONESE, A.E. Y MARTINEZ CROVETTO, R. 1947. Plantas indígenas de la Argentina con frutos o semillas comestibles. Revista de Investigaciones Agricolas 1: 147217.

28.- REYNOLDS, M. 2008. Antimicrobial and pesticidal compositions and methods comprising reduced monoterpene oil extracted from Myrtaceae. Patente US20080026083 A1, recibida el 17 de julio de 2007, y emitida el 31 de enero de 2008. http://www.google. com/patents/US20080026083.

29.- SANTOS, A.F. DOS; SILVA, S. DE M.; NUNES MENDOÇA, M. Y CUNHA FILGUEIRAS, E.A. 2006. Storage of suriname cherry under modified atmosphere and refrigeration: II - Quality and posharvest conservation. Revista Brasileira de Fruticultura 28: 42-45.

30.- SANTOS, A.F. DOS; SILVA, S. DE M. Y ALVES, R.E. 2006. Storage of suriname cherry under modified atmosphere and refrigeration: I-postharvest chemical changes. Revista Brasileira de Fruticultura 28: 36-41.
31.- SCHMEDA-HIRSCHMANN, G.; FERESIN, G.; TAPIA, A.; HILGERT, N. Y THEODULOZ, C. 2005. Proximate composition and free radical scavenging activity of edible fruits from the Argentinian Yungas. Journal of the Science of Food and Agriculture 85: 1357-1364.

32.- SEERAM, N.P. 2008. Berry Fruits: Compositional Elements, Biochemical Activities, and the Impact of Their Intake on Human Health, Performance, and Disease. Journal of Agricultural and Food Chemistry 56: 627629.

33.- TEL-ZUR, N. Y SCHNEIDER, B. 2009. Floral biology of Ziziphus mauritiana (Rhamnaceae). Sexual Plant Reproduction 22: 73-85.

34.- USO SOSTENIBLE BIODIVERSIDAD. (s. f.). En: http://www.ar.undp.org/content/ argentina/es/home/operations/projects/environment_and_energy/ENBiodiversidad. html. Acceso: 28/06/2018.

35.- VIZZOTTO, M.; CABRAL, L. Y SANTOS, A. 2011. 13 - Pitanga (Eugenia uniflora L.) A2 - Yahia, Elhadi M. Postharvest Biology and Technology of Tropical and Subtropical Fruits. Woodhead Publishing. p.272-288e.

36.- WIRTH, C. 2014. Extracts from Eugenia uniflora. Patente WO2012163469 A3, recibida el 9 de mayo de 2012, y emitida el 30 de enero de 2014. http://www.google.com/ patents/WO2012163469A3. 